\title{
Pesquisa debactérias patogênicas em leite pasteurizado tipo C comercializado na cidade do Recife, Pernambuco, Brasil
}

\author{
Investigation of pathogenic bacteria in pasteunized type $C$ \\ milk sold in Recife City, Pemambuco, Brazil
}

\author{
Maria do Rosário de Fátima Padilha', Zelyta de Faro Fernandes', Tereza Cristina Arcanjo Leal' \\ Nilma Cintra Leal ${ }^{2}$ e Alzira Maria Paiva de Almeida ${ }^{2}$
}

\begin{abstract}
Resumo Visando complementar as informações sobre a qualidade microbiológica do leite comercializado na cidade do Recife, foram analisadas 250 amostras de leite pasteurizado tipo C e 50 amostras de leite cru para a pesquisa de Yersinia enterocolitica e Listeria monocytogenes, bactérias patogênicas capazes de se desenvolverem em temperatura de refrigeração. $Y$. enterocolitica não foi encontrada em nenhuma das amostras analisadas, entretanto foi detectada a presença de $Y$. intermedia e $Y$. frederiksenii, espécies ambientais que se comportam como patógenos oportunistas. L. monocytogenes também não foi encontrada, mas, através da metodologia empregada para seu isolamento foi obtido um isolamento de Salmonella Montevideo em uma amostra de leite pasteurizado e outro em leite cru. Além dessas, várias outras bactérias foram encontradas, supondo-se que a ampla microbiota crescida nos meios empregados pode ter interferido no isolamento da Y. enterocolitica e L. monocytogenes.
\end{abstract}

Palavras-chaves: Leite. Yersinia. Listeria. Salmonella.

Abstract In order to improve information about the microbiological quality of the milk commercially available in the city of Recife, 250 samples of pasteurized type-C milk and 50 samples of raw milk were analyzed for Yersinia enterocolitica and Listeria monocytogenes and verify the possible occurrence of Yersinia enterocolitica and Listeria monocytogenes. These bacteria can develop in refrigeration temperatures and are responsible for food-born diseases. Neither $Y$. enterocolitica nor L. monocytogenes were found in the samples analyzed. However, the presence of $Y$. intermedia and $Y$. frederiksenii was detected, these environmental species behave as opportunist pathogens. Through the methodology used for Listeria isolation, one isolate of Salmonella Montevideo was obtained from a sample of pasteurized milk and another isolated from one sample of raw milk. Besides these, several other bacteria species were found. It is likely that the large microbiota present in the samples and the procedures employed to destroy it could have hindered the isolation of Y. enterocolitica and L. monocytogenes.

Key-words: Milk. Yersinia. Listeria. Salmonella.

A higiene e o controle do leite e produtos lácteos têm como objetivo básico assegurar a sua inocuidade ao consumidor. A contaminação com certos microrganismos e/ou suas toxinas, constituem as causas mais freqüentes de problemas sanitários, além das perdas econômicas.

Concernente à microbiota presente no leite, Yersinia enterocolitica e Listeria monocytogenes têm recebido especial atenção nos últimos anos, porque causam doenças de origem alimentar ${ }^{510}$ e têm a capacidade de se desenvolver em temperatura de refrigeração, fator preocupante para a indústria de alimentos.
Apesar dos registros sobre a ocorrência de $Y$. enterocolitica em leite e derivados no Sudeste do Brasil $^{7} 821$, na Região Nordeste a literatura é bastante escassa $^{13}$ acerca de tão importante tema, apesar do leite constituir um dos alimentos mais consumidos pelas populações, em todas as faixas etárias.

O presente estudo analisou a possível ocorrência de $Y$. enterocolitica e L. monocytogenes, em amostras de leite pasteurizado tipo $\mathrm{C}$, comercializado no Estado de Pernambuco, proveniente de usinas de beneficiamento que, segundo Padilha \& Fernandes ${ }^{18}$ apresentavam condições fora dos padrões do Ministério da Saúde.

${ }^{1}$ Departamento de Nutrição da Universidade Federal de Pernambuco, ${ }^{2}$ Departamento de Microbiologia do Centro de Pesquisas Aggeu Magalhães. Recife, PE. Projeto financiado pela FACEPE, Processo (APQ - $0315-2.12 / 94$ )

Endereço para correspondência: Dra Alzira de Almeida. CPqAM/FIOCRUZ/MS. Campus da UFPE, Cidade Universitária,Caixa Postal 7472. 50670-420 Recife, PE, Brasil.

Tel: 5581 3301-2568 Fax: 5581 3453-2449

e-mail: aalmeida@cpqam.fiocruz.br

Recebido para publicação em 19/5/2000 


\section{MATERIAL E MÉTODOS}

Amostragem. Foram coletadas 250 amostras provenientes de cinco diferentes marcas de leite pasteurizado tipo C e 50 de leite cru no período entre setembro de 1994 a junho de 1995. As coletas foram realizadas semanalmente, sendo o leite pasteurizado tipo C (1 litro) adquirido aleatoriamente, em estabelecimentos varejistas da cidade do Recife (supermercados, padarias e mercearias) proveniente de usinas de tratamento abastecidas pelo leite da bacia leiteira da Região Agreste de Pernambuco. O leite cru usado como controle, foi adquirido em três vacarias da Região Metropolitana do Recife, acondicionado em vidros esterilizados de 1 litro. As amostras coletadas foram imediatamente transportadas em caixas isotérmicas com gelo para o Laboratório de Experimentação e Análise de Alimentos (LEAAL) do Departamento de Nutrição da Universidade Federal de Pernambuco.

Pesquisa de Yersinia enterocolitica. Alíquotas de $25 \mathrm{ml}$ de cada amostra eram homogeneizadas em $225 \mathrm{ml}$ de solução tampão fosfato (PBS) $\mathrm{pH} \mathrm{7,6} \mathrm{e}$ incubadas a $4^{\circ} \mathrm{C}$ por 21 dias. Em seguida, após agitação por 15min, uma alça do sobrenadante era plaqueada no Agar Cefsulodin-Irgasan-Novobiocina $(\mathrm{CIN})^{19}$, efetuando-se nova incubação a $25^{\circ} \mathrm{C}$ por 24 a 48h. Colônias com morfologia característica eram repicadas em Agar Casoy e incubadas a $25^{\circ} \mathrm{C}$ por $48 \mathrm{~h}$, incluindo-se a seguinte triagem preliminar: teste da motilidade e as reações nos meios Agar Tríplice Açúcar Ferro (TSI), Agar Uréia e Agar Citrato de Simmons. A identificação foi complementada pelo sistema API 20E, usando como controle uma cepa de referência $Y$. enterocolitica (AM 151).

Pesquisa de Listeria monocytogenes. Homogeneizouse $25 \mathrm{ml}$ de cada amostra em $225 \mathrm{ml}$ de caldo de enriquecimento seletivo para Listeria-Oxford (Difco) que foi incubado a $30^{\circ} \mathrm{C}$. Após $24 \mathrm{~h}$, $48 \mathrm{~h}$ e 7 dias, alíquotas em duplicata de $0,1 \mathrm{ml}$ foram transferidas para placas de agar seletivo para Listeria-Oxford (Difco) e incubadas a $37^{\circ} \mathrm{C}$ por 24 e $48 \mathrm{~h}$. Colônias com morfologia característica eram repicadas em agar TSYEA (caldo casoy $+9 \%$ extrato de levedura), incubadas a $37^{\circ} \mathrm{C}$ por $24 \mathrm{~h}$ e então submetidas aos testes bioquímicos para identificação. Como controle foram usadas as cepas L. monocytogenes F45555-4b, L. ivanovii E4081, L. innocua 12624, L. welshimeri 11633 e L. seeligeri 9529, obtidas por cortesia do Dr. Ernesto Hofer do Departamento de Bacteriologia do IOC/FIOCRUZ.

Antibiograma. A susceptibilidade aos antimicrobianos foi avaliada pelo método de difusão de discos ${ }^{1}$ utilizando-se o Agar Mueller-Hilton e discos (Biolab, CECON) impregnados com ácido nalidíxico (30mcg), ampicilina $(10 \mathrm{mcg})$, carbenicilina $(100 \mathrm{mcg})$, cefalotina $(30 \mathrm{mcg})$, cefoxitina $(30 \mathrm{mcg})$, ceftazidime $(30 \mathrm{mcg})$, clindamicina $(2 \mathrm{mcg})$, cloranfenicol $(30 \mathrm{mcg})$, gentamicina $(100 \mathrm{mcg})$, kanamicina $(30 \mathrm{mcg})$, imipenem $(10 \mathrm{mcg})$, lincomicina $(2 \mathrm{mcg})$, rifampicina $(5 \mathrm{mcg})$, sulfazotrin $(25 \mathrm{mcg})$ e tetraciclina (30mcg). Para controle foi utilizada a cepa de referência Escherichia coli ATCC 25922.

Técnicas moleculares. Para verificar a presença de plasmídeos em isolados de yersínia e salmonela, o DNA plasmidial das amostras foi extraído pela técnica de Birnboim \& Doly ${ }^{4}$ usando como controle uma cepa de $Y$. enterocolitica O:3, biotipo 4, fagotipo VIII e a cepa Yersinia pestis EV76. Como referência de peso molecular foram usados os plasmídios da cepa Escherichia coli 39R861 (NCTCC-PHL). O DNA genômico foi extraído segundo Maniatis et al $^{15}$ e quantificado por comparação com quantidade conhecida de DNA do fago I clivado pela enzima Hind III, em eletroforese em gel de agarose a $1 \%$.

Os isolados de salmonelas foram analisados por RAPD-PCR seguindo a metodologia descrita por Leal et $\mathrm{al}^{14}$. Foram realizados ensaios preliminares com 16 iniciadores (primers) construídos para diversos fins e o DNA de um isolado de Salmonella Montevideo para seleção dos primers capazes de gerar bandas nítidas e reprodutíveis. As amplificações foram realizadas em um termociclador (Perkin Elmer) programado para 30 ciclos compostos de $1 \mathrm{~min}$ a $94^{\circ} \mathrm{C}, 1 \mathrm{~min}$ a $36^{\circ} \mathrm{C}$ e $2 \min$ a $72^{\circ} \mathrm{C}$, terminando por $7 \mathrm{~min}$ a $72^{\circ} \mathrm{C}$. As reações foram preparadas em um volume final de $25 \mu \mathrm{l}$ por tubo, contendo 20 ng do DNA purificado, $1 \mathrm{U}$ da enzima TaqDNA polimerase (CENBIOT/RS), 10mM de Tris- $\mathrm{HCl}, 3 \mathrm{mM}$ de $\mathrm{MgCl}_{2}$, $50 \mathrm{mM}$ de $\mathrm{KCl}, 200 \mu \mathrm{M}$ de cada desoxirribonucleotídeo (Pharmacia) e 20pmol de cada iniciador. Os produtos das amplificações foram submetidos a eletroforese em gel de agarose 1,5\%, em tampão Tris-borato e voltagem constante de $100 \mathrm{~V}$, seguido de coloração com brometo de etídio, visualizados em UV e fotografados por Polaroide. A reprodutibilidade dos resultados das amplificações foi avaliada pela repetição das reações de PÇR no mínimo três vezes. Em cada partida de amplificação foi incluído um controle negativo que consistia de um tubo contendo todos os componentes da mistura de reação, exceto o DNA.

\section{RESULTADOS E DISCUSSÃO}

Diversos fatores como a deficiência no controle sanitário do rebanho leiteiro, a falta de higiene na obtenção do produto, a ausência de uma infra-estrutura adequada de transporte até os locais de processamento e a precariedade dos sistemas de refrigeração, contribuem para a má qualidade microbiológica do leite.

A presença de Yersinia enterocolitica não foi detectada em nenhuma das amostras de leite 
analisadas. Leal et $\mathrm{al}^{13}$ também não detectaram a presença dessa bactéria em alimentos e reservatórios animais na região, embora a identificação de $Y$. enterocolitica, nos laboratórios de análises locais seja muito rara, com eventuais registros $^{812}$ mas sem a conotação de uma fonte de infecção e via de transmissão. A partir de duas amostras de leite cru, foram obtidos um isolado de $Y$. intermedia e um de $Y$. frederiksenii. Estas espécies são encontradas no ambiente e se comportam como patógenos oportunistas, eventualmente produtoras de enterotoxina estável ao calor ${ }^{17}$.

Salienta-se que na pesquisa de $Y$. enterocolitica, recorrendo-se ao meio seletivo-indicador - $\mathrm{CIN}^{19}$ predominou 0 isolamento de contaminantes representados por Klebsiella sp, Enterobacter sp, Citrobacter sp, Erwinia sp, Serratia sp, Pseudomonas sp e Aeromonas hydrophila além das duas espécies de Yersinia: Y. intermedia e $Y$. frederiksenii. Por sinal, outros autores ${ }^{71}$ observaram o mesmo fato, isto é, a discreta seletividade do meio CIN, como resultado provável da competição microbiana interferindo no isolamento de $Y$. enterocolitica ${ }^{20}$.

L. monocytogenes não foi detectada em nenhuma das amostras de leite cru ou pasteurizado com a metodologia adotada. Entretanto, as análises microbiológicas evidenciaram a presença de outros microrganismos grampositivos e gram-negativos dos gêneros Enterobacter, Citrobacter, Erwinia, Klebsiella, Serratia, Pseudomonas, Aeromonas e Bacillus. Segundo Breer \& Schopfer ${ }^{6}$ e Farber ${ }^{9}$, como normalmente $L$. monocytogenes, se encontra nos alimentos em baixas concentrações, seu crescimento pode ser sobrepujado pelos contaminantes. Além da presença da ampla microbiota detectada nas amostras, os processos físicos e químicos empregados para destruí-la ${ }^{18}$, podem ter comprometido o isolamento da $L$. monocytogenes.
Surpreendentemente, com a metodologia empregada para a pesquisa de $L$. monocytogenes, foi encontrado Salmonella Montevideo em uma amostra de leite cru proveniente de vacaria e outra de leite pasteurizado. Segundo Bailey et $a^{3}$ alguns meios de enriquecimento utilizados na recuperação de Listeria em alimentos não contêm suficiente tampão para prevenir uma rápida queda do $\mathrm{pH}$, favorecendo o isolamento de outros organismos e dificultando a recuperação da Listeria. Além disso Bailey \& Cox $^{2}$ não observaram inibição de Salmonella pela competição com Listeria em um meio de enriquecimento para Listeria e Salmonella, mas com redução do crescimento de Listeria em torno de 3 logaritmos em presença da Salmonella. Estas observações poderiam explicar a presença de Salmonella num meio específico para recuperar Listeria, cuja formulação consta de inibidores para microrganismos gram-negativos.

A presença de Salmonella no leite pasteurizado é preocupante, uma vez que este microrganismo figura como uma importante causa de toxinfecção alimentar. Vale salientar que a mesma amostra foi também avaliada para pesquisa de Salmonella, segundo a técnica preconizada pelo Ministério da Agricultura ${ }^{16}$, tendo apresentado resultado negativo ${ }^{18}$.

A análise do conteúdo plasmidial das amostras de $Y$. intermedia e $Y$. frederiksenii e dos dois isolados de $S$. Montevideo não evidenciou a presença de plasmídios.

Quanto à susceptibilidade, aos antimicrobianos, a amostra de Y. intermedia isolada apresentou resistência à cefalotina, clindamicina, lincomicina, ampicilina, carbenicilina e kanamicina, enquanto a Y. frederikseniifoi resistente apenas à cefalotina, clindamicina e lincomicina. Quanto aos isolados de $S$. Montevideo, foi grande a sensibilidade apresentada, uma foi resistente apenas à kanamicina e a outra ao sulfazotrim (Tabela 1 ).

Tabela 1 - Susceptibilidade dos isolados de Yersinia intermedia, Yersinia frederiksenii e Salmonella Montevideo originados das amostras de leite cru ou pasteurizado aos agentes antimicrobianos.

\begin{tabular}{lcccc}
\hline Antimicrobianos & \multicolumn{2}{c}{ Yersinia } & & \multicolumn{2}{c}{ Salmonella Montevideo } \\
\cline { 2 - 5 } & intermedia & frederiksenii & isolado 1 & isolado 2 \\
Ácido nalidíxico & $\mathrm{S}$ & $\mathrm{S}$ & $\mathrm{S}$ & $\mathrm{S}$ \\
Carbenicilina & $\mathrm{R}$ & $\mathrm{S}$ & $\mathrm{S}$ & $\mathrm{S}$ \\
Cefalotina & $\mathrm{R}$ & $\mathrm{S}$ & $\mathrm{Na}$ & $\mathrm{Sa}$ \\
Cefoxitina & $\mathrm{R}$ & $\mathrm{R}$ & $\mathrm{Na}$ & $\mathrm{S}$ \\
Clindamicina & $\mathrm{Na}$ & $\mathrm{Na}$ & $\mathrm{S}$ & $\mathrm{Na}$ \\
Ceftazidime & $\mathrm{R}$ & $\mathrm{S}$ & $\mathrm{S}$ \\
Cloranfenicol & $\mathrm{Na}$ & $\mathrm{Na}$ & $\mathrm{Na}$ & $\mathrm{S}$ \\
Gentamicina & $\mathrm{S}$ & $\mathrm{S}$ & $\mathrm{S}$ & $\mathrm{Na}$ \\
Imipenem & $\mathrm{S}$ & $\mathrm{S}$ & $\mathrm{R}$ & $\mathrm{S}$ \\
Kanamicina & $\mathrm{Na}$ & $\mathrm{Na}$ & $\mathrm{S}$ \\
Lincomicina & $\mathrm{R}$ & $\mathrm{S}$ & $\mathrm{R}$ & $\mathrm{Na}$ \\
Rifampicina & $\mathrm{R}$ & $\mathrm{R}$ & $\mathrm{S}$ & $\mathrm{R}$ \\
Sulfazotrim & $\mathrm{Na}$ & $\mathrm{Na}$ & $\mathrm{R}$ & $\mathrm{R}$ \\
Tetraciclina & $\mathrm{Na}$ & $\mathrm{Na}$ & $\mathrm{R}$ & \\
\hline
\end{tabular}

$\mathrm{S}=$ sensível $\mathrm{R}=$ resistente $\quad \mathrm{I}=$ intermediário $\quad \mathrm{Na}=$ não avaliado 
Os diferentes perfis de susceptibilidade aos antimicrobianos dos dois isolados de S. Montevideo sugerem que as duas amostras diferem entre si. Entretanto, através da análise por RAPD-PCR com os dois primers selecionados (785: 5'-CCGCAGCCAA-3' e 797: - 5'AGCGTCACTG-3') as duas amostras apresentaram o mesmo padrão caracterizado pela amplificação de igual número de bandas, específico com cada um dos primers. A amplificação com o primer 785 gerou 7 bandas bem definidas e reprodutíveis de 600 a 2400 pares de base (pb) e com o primer 797 foram amplificadas 3 bandas de 600 a 1600pb (Figura 1).

Embora não tenham sido detectadas $Y$. enterocolitica nem $L$. monocytogenes com a metodologia dirigida ao isolamento dessas espécies, outras bactérias foram encontradas, inclusive Salmonella. Esses achados se revestem de grande importância considerando que estas bactérias não foram inibidas mesmo com a utilização de processos de superaquecimento $(61,2 \%$ das amostras) e adição de peróxido de hidrogênio $(7,2 \%$ das amotras), usados com fins bactericidas e evidenciados por Padilha \& Fernandes ${ }^{18}$.

Destaca-se que esses procedimentos são proibidos no Brasil, considerados como adulteração do produto e mesmo assim não foram suficientemente eficazes para destruir a flora microbiana das amostras.
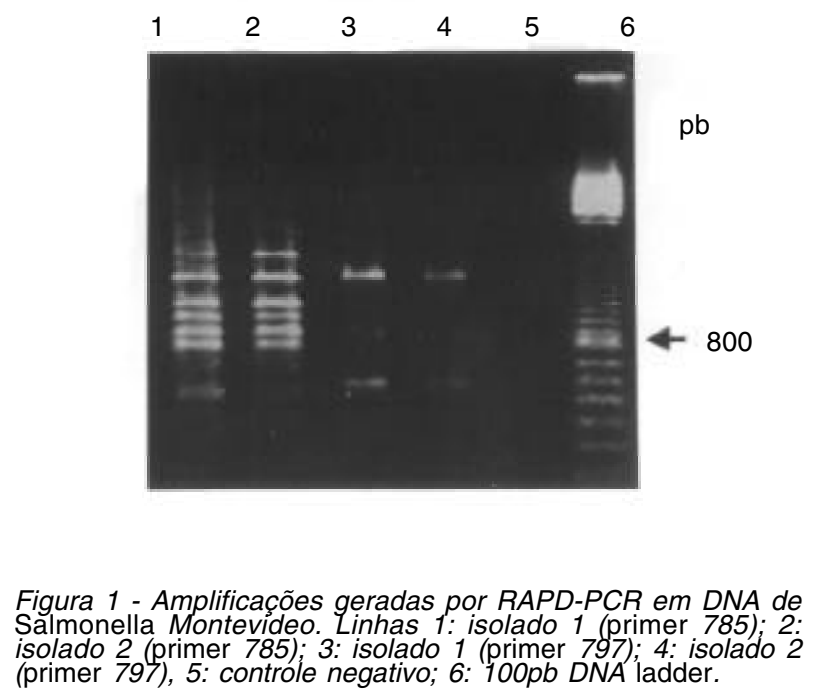

Salmonella Montevideo. Linhas 1: isolado 1 (primer 785); 2 : (primer 797), 5: controle negativo; 6: 100pb DNA ladder.

\section{AGRADECIMENTOS}

À Sr ${ }^{\text {a }}$. Yara Nakasawa por colaborar na realização dos antibiogramas e ao Dr. Ernesto Hofer, pelas valiosas sugestões e fornecimento de cepas controle.

\section{REFERÊNCIAS BIBLIOGRÁFICAS}

1. Bauer W, Kirby WMM, Shevis JC, Turck M. Antibiotic susceptibility testing by a standardized single disk method. American Journal of Clinical Pathology 45:493,1966.

2. Bayley JS, Cox NA. A universal preenrichment broth for the simultaneous detection of Salmonella and Listeria in foods. Journal of Food Protection 55:256-259, 1992.

3. Bayley JS, Fletcher DL, Cox NA. Efficacy of enrichment media for recovery of heat-injured Listeria monocytogenis. Journal of Food Protection 53:473-477, 1990.

4. Birboim HC, Doly J. A rapid alkaline procedure for screening recombinant plasmid DNA. Nucleic Acids Research 6:1513-1523, 1979.

5. Bottone EJ. Yersinia enterocolitica: the charisma continues Clinical Microbiological Reviews 10:257-276, 1997.

6. Breer C, Schopfer K. Listeria and food. Lancet 2:1022, 1988.
7. Eiroa UMN, Cullen BT, Falcão DP, Leitão MFF. Yersinia enterocolitica e Yersinia atípica em leite cru e pasteurizado. Coletânea do Instituto de Tecnologia de Alimentos 14:27-37, 1984.

8. Falcão DP. Ocorrence of Yersinia sp in foods in Brazil. International Journal of Food Microbiology, Amsterdam 14:179-182, 1991.

9. Farber JM. Thermal resistance of Listeria monocytogenis in foods. International Journal of Food Microbiology 8:285-291, 1989.

10. Fleming DW, Cochi SL, MacDonald KL, Brondum J, Hayes PS, Plikaytis BD, Holmes MB, Audurier A, Broome CV, Reingold AL. Pasteurized milk as a vehicle of infection in an outbreak of listeriosis. The New England Journal of Medicine 312:404-407, 1985.

11. Gilmour A, Walker SJ. Isolation and identification of Yersinia enterocolitica and the Yersinia enterocolitica-like bacteria. Journal of Applied Bacteriology 65: (Suppl.):133-138, 1988. 
12. Leal NC, Cavalcanti TIR, Silva MJB, Reis EMF, Solari CA, Hofer E. Frequência de enterobactérias patogênicas em processos diarréicos infantis na cidade do Recife, Pernambuco Brasil. Memórias do Instituto Oswaldo Cruz 83:475-479, 1988.

13. Leal TCA, Leal NC, Almeida AMP. Ausência de Yersinia enterocolitica em alimentos e reservatórios animais, em áreas do estado de Pernambuco, Brasil. Revista da Sociedade Brasileira de Medicina Tropical 30:193-196, 1997

14. Leal TCA, Leal NC, Almeida AMP. RAPD-PCR typing of Yersinia enterocolitica (Enterobacteriaceae) 0:3 serotype strains isolated from pigs and humans. General Molecular Biology 22:315-319, 1999.

15. Maniatis T, Fritsch EF. Sambrook J. Molecular cloning: a laboratory manual. Cold Spring Harbour: Cold Spring Harbour Laboratory, 1989.

16. Ministério da Agricultura. Portaria oo 101 de 11 de agosto de 1993 Aprova os Métodos de análise microbiológica para alimentos. Diário Oficial da República Federativa do Brasil, s.1:11.93711.960, 17.08, 1993
17. Nunes MP. Invasibilidade e enterotoxigenicidade de Yersinia enterocolitica e das espécies atípicas de Yersinia isoladas do homem e de cães no Brasil. Revista de Microbiologia 15:222226, 1984.

18. Padilha MRF, Fernandes ZF. Avaliação da qualidade higiênicosanitária do leite tipo "C" comercializado no Recife-PE. Higiene Alimentar 13:105-109, 1999.

19. Schiemann DA. Synthesis of a selective agar medium for Yersinia enterocolitica. Canadian Journal of Microbiology 25:12981304, 1979.

20. Stern NJ, Pierson MD, Kotula W. Effects of $\mathrm{pH}$ and sodium chloride on Yersinia enterocolitica growth at room and refrigeration temperatures. Journal of Food Science 45:64-67, 1980.

21. Tibana A, Warnken MB, Nunes MP, Ricciardi ID, Noleto AS. Occurrence of Yersinia species in raw and pasteurized milk in Rio de Janeiro, Brazil. Journal of Food Protection 50:580-583, 1987. 